\title{
PREDICTIVE VALUE OF ADMISSION CARDIOTOCOGRAM TEST IN PERINATAL OUTCOME
}

\author{
Murugan Indira1, Srinivasan Padma², Vignesh Mani ${ }^{3}$
}

${ }^{1}$ Assistant Professor, Department of Obstetrics and Gynaecology, IRT-PMCH.

${ }^{2} \mathrm{HOD}$ and Senior Consultant, Department of Obstetrics and Gynaecology, Meenakshi Mission Hospital and Research Centre. 3Junior Resident, Department of Obstetrics and Gynaecology, IRT-PMCH.

ABSTRACT
BACKGROUND
The present study was undertaken to test the reliability of admission test to identify compromised foetuses and to correlate the
test results with different parameters of adverse foetal outcome and mode of delivery.

\section{MATERIALS AND METHODS}

An admission Foetal Heart Rate (FHR) tracings was obtained by cardiotocogram on 100 antenatal mothers, both high and low risk in early labour for 20 minutes and then categorised based on RCOG criteria for interpretation of admission test. Perinatal outcome and mode of delivery were analysed with the help of Kruskal-Wallis chi square test.

\section{RESULTS}

1. Preeclampsia was the most common high risk factor in our study.

2. Mean gestational age at delivery in high risk group was 37 weeks compared to 39 weeks in low risk group.

3. The percentage of LSCS is more in non-reactive tracings, but this value is not statistically significant as p value is 0.0524 in high risk group and 0.0636 in low risk group.

4. In high risk category in non-reactive group, 6 out of 9 i.e. $66.7 \%$ had low Apgar score making the p value 0.0001 , which is statistically significant.

5. The duration of hospital stay was also more in babies with non-reactive tracings, a mean of 7 days as compared to 5 days in reactive group in high risk patients. This value is statistically significant as the $\mathrm{p}$ value is 0.04 .

6. The specificity of admission test in predicting perinatal mortality in high risk pregnancies is quite high; it is $95 \%$ and the negative predictive value is $93 \%$. The sensitivity of the test is $70 \%$ and positive predictive value is found to be $78 \%$.

\section{CONCLUSION}

By analysing our study carefully and comparing it with similar studies in literature we can conclude any non-reactive tracings should be extended for 40 minutes along with foetal stimulation to reduce the false positive rates. Admission test increases the rate of LSCS in both high and low risk groups. Non-reactive traces in both high and low risk groups are associated with more foetal distress, low Apgar, prolonged NICU care and increased perinatal mortality.

\section{KEYWORDS}

Admission Test (AT), Non-Stress Test, Reactive Trace, Non-Reactive Trace, Foetal Heart Rate (FHR).

HOW TO CITE THIS ARTICLE: Indira M, Padma S, Mani V. Predictive value of admission cardiotocogram test in perinatal outcome. J. Evolution Med. Dent. Sci. 2017;6(22):1794-1798, DOI: 10.14260/Jemds/2017/394

\section{BACKGROUND}

The purpose of obstetric care is to optimise maternal and foetal safety. The clinical decisions are always a balance between the risk to the foetus if undelivered and the risk to the mother and foetus if the pregnancy continues. In an attempt to stratify the risk, a variety of screening tests are performed during prenatal and intrapartum periods to identify high risk population.

These include detailed patient history, physical examination, laboratory tests - non-stress test, contraction stress test, sonographic assessment of foetal biophysical profile, Vibroacoustic stimulation, amniotic fluid assessment, Doppler velocimetry. There is no single test that is ideal for all high risk foetuses.

Financial or Other, Competing Interest: None.

Submission 22-01-2017, Peer Review 21-02-2017,

Acceptance 27-02-2017, Published 16-03-2017.

Corresponding Author:

Dr. Murugan Indira,

A2, SMQ, Sanatorium,

Perundurai, Erode-638053.

E-mail: drindiradgo@gmail.com

DOI: $10.14260 /$ jemds $/ 2017 / 394$ (c) $(1) \odot$
The "Admission" Cardiotocogram 1

Dynamic screening test for the state of oxygenation of the foetus on admission of mother to labour room, to detect compromised foetuses. It assesses the placental reserve by checking the response of FHR during the phase of temporary occlusion of uteroplacental blood supply. The incidence of emergency caesarean section for foetal distress is higher in the first hour of labour than in any subsequent single hour. This is because the onset of contraction reveals the foetus that is unable to cope with the relative hypoxia of labour. Such foetuses may then be delivered or subjected to additional tests of foetal surveillance like continuous CTG (Cardiotocography) throughout labour in order to prevent adverse outcomes.

\section{Advantages of Admission CTG over Auscultation}

A crucial advantage of the admission CTG is the ability to assess all parameters of foetal heart rate including baseline variability. Presence of accelerations, normal baseline heart rate, variability more than $5 \mathrm{bpm}$ and absence of any decelerations are features of a normal reassuring CTG.(2) Although, auscultation may provide the baseline foetal heart rate and indicate presence of accelerations/decelerations - 
baseline variability is not audible to the unaided ear and quantification/description of type of decelerations may be difficult.

The admission CTG being a visual test can make patients as well as clinicians feel reassured that the foetus is not at risk of hypoxia at the time of admission and is unlikely to develop hypoxia in the next few hours.

For this reason, performing electronic foetal monitoring in for the first hour of labour even in low risk pregnancies ("Admission test") has become popular in some maternity units, unfortunately no studies of sufficient size have been conducted to enable an evolution of the usefulness of this approach.

In this study, effectiveness and the role of admission stress test has been evaluated for assessing the perinatal outcome of foetuses in both high and low risk pregnancies.

\section{MATERIALS AND METHODS}

This prospective study was undertaken in (Meenakshi Mission Hospital and Research Centre from Dec. 2011 to Dec. 2012); 50 high risk patients and 50 low risk patients were studied.

\section{Inclusion Criteria}

1. Patients of all age groups who give informed consent.

2. Singleton, non-anomalous pregnancies of 32 weeks or more weeks of gestation delivering at MMHRC.
Inclusion Criteria for High Risk Group

- Pregnancy-induced hypertension.

- Gestational diabetes mellitus.

- Intrauterine growth restriction.

- Post-term pregnancy.

- Premature Rupture of membranes > 6 Hours.

- Oligohydramnios.

- History of recurrent pregnancy losses, stillbirth.

- Pregnancies with medical illnesses like hypertension, diabetes mellitus, renal disease, thrombophilia, antiphospholipid antibody syndrome.

\section{The Exclusion Criterion Includes}

- Mal-presentations, previous LSCS and cephalopelvic disproportion, multiple pregnancies.

- Gestational age of $<32$ wks.

- Major congenital anomaly.

\section{METHODS}

An admission FHR tracing was obtained by cardiotocogram on all admitted patients in early labour. The cardiotocographic equipment of BPL FM 9854 was applied to the maternal abdomen and patient was instructed to push the event marker button every time she felt foetal movement. An FHR tracing was obtained for 20 minutes and then categorised as normal, suspicious or abnormal based on -

RCOG Criteria for Interpretation of Admission Test

\begin{tabular}{|c|c|c|c|c|}
\hline Feature & Baseline (bpm) & Variability (bpm) & Decelerations & Accelerations \\
\hline Reassuring & $110-160$ & $\geq 5$ & None & $>2$ \\
\hline Non-Reassuring & $\begin{array}{l}100-109 \\
161-180\end{array}$ & $\begin{array}{l}<5 \text { for }>40 \text { to } \\
<90 \text { minutes }\end{array}$ & $\begin{array}{c}\text { Early deceleration } \\
\text { Variable } \\
\text { deceleration } \\
\text { Single prolonged } \\
\text { deceleration up to } \\
3 \text { minutes } \\
\end{array}$ & $\begin{array}{c}\text { The absence of } \\
\text { accelerations } \\
\text { with an otherwise } \\
\text { normal CTG } \\
\text { are of uncertain } \\
\text { significance }\end{array}$ \\
\hline Abnormal & $\begin{array}{c}<100 \\
>180 \\
\text { Sinusoidal } \\
\text { pattern } \geq 10 \\
\text { minutes }\end{array}$ & $\begin{array}{c}<5 \text { for } \geq 90 \\
\text { minutes }\end{array}$ & $\begin{array}{c}\text { Atypical variable } \\
\text { decelerations } \\
\text { Late decelerations } \\
\text { Single prolonged } \\
\text { Single prolonged } \\
\text { deceleration }>3 \\
\text { minutes }\end{array}$ & $\begin{array}{c}\text { The absence of } \\
\text { accelerations } \\
\text { with an otherwise } \\
\text { normal CTG } \\
\text { are of uncertain } \\
\text { significance }\end{array}$ \\
\hline
\end{tabular}

\begin{tabular}{|c|c|}
\hline Category & Definition \\
\hline Normal & All four features fall into the reassuring category \\
\hline Suspicious & $\begin{array}{c}\text { A CTG whose features fall into one of the non-reassuring categories } \\
\text { and the remainder of the features are reassuring }\end{array}$ \\
\hline Pathological & $\begin{array}{c}\text { A CTG whose features fall into two or more non-reassuring categories } \\
\text { or one or more abnormal categories }\end{array}$ \\
\hline \multicolumn{2}{|c|}{ Table 2} \\
\hline
\end{tabular}

Extended up to 40 minutes for the non-reactive traces.

\section{Outcome}

The patients were then followed up for the mode of delivery and perinatal outcome. At the time of delivery following data variables were collected - perinatal mortality, foetal distress during labour, 5 mins Apgar score of $>5$, Meconium Stained Amniotic Fluid (MSAF), duration of NICU care.

\section{Statistical Tools}

Using Epidemiological Information Package (EPI 2002) software, range, frequencies, percentages, means and 
standard deviations were calculated. Kruskal-Wallis chisquare test was used to test the significance of difference between quantitative variables and Yate's chi square test for qualitative variables. A ' $p$ ' value less than 0.05 is taken to denote significant relationship.

\section{Result Analysis}

The mean age for high risk pregnancy and low risk pregnancy were 26.5 years and 25.9 years respectively. Most of the patients attending our hospital were from class 3 socioeconomic status.

The mean gestational age in High Risk (HR) group was 37 weeks at delivery, whereas in Low Risk (LR) group the mean gestational age was 39 weeks. This is statistically significant as the $\mathrm{p}$ value is .00001 .

Lower gestational age at delivery in high risk group was due to preterm PROM, severe preeclampsia, IUGR, warranted early delivery in this group. Also, percentage of non-reactive admission test was more in high risk group leading to early delivery of baby.

Maximum number of patients in our study had more than one high risk factor. Preeclampsia is the most common risk constituting $42 \%$ of the total cases high risk factor in our study.

Comparing the admission test results, the total percentage of non-reactive test in our study was $22 \%$. The percentage of non-reactive admission test (18\%) in high risk group was more than reactive (4\%), but it is not statistically significant as $p$ value is 0.05 .

Comparing, the rate of LSCS in reactive and non-reactive traces the rate of LSCS in non-reactive high risk group was $88.9 \%$ and in reactive case it was $53.7 \%$. While the rate of LSCS in low risk group in non-reactive cases was $100 \%$ and $22.9 \%$ in reactive traces.

In high risk non-reactive group, non-reactive admission test with unfavourable cervix was the most common indication for LSCS constituting $43.3 \%$ of cases followed by foetal distress $13.3 \%$, meconium stained liquor $13.3 \%$, failed induction $10 \%$ and non-progression of labour.

\section{LSCS for Intrapartum Foetal Distress}

In low risk patients in non-reactive category there were two patients, both were delivered by LSCS and one had thick meconium stained liquor, other patient had intrapartum foetal distress.

Out of 100 patients, clinical foetal distress was seen in 8 out of 89 reactive traces $(8.9 \%)$ and 2 out of 12 of nonreactive traces $(18 \%)$. In high risk group, 3 out of 41 reactive traces had clinical foetal distress, $(7 \%)$ one out of 8 nonreactive had intrapartum foetal distress $(12 \%)$.

In low risk group 4 out of 48 reactive traces had intrapartum distress (8.3\%), one of two patients had intrapartum foetal distress (50\%). Thus, clinically detected foetal distress was more common in non-reactive traces in both high and low risk cases compared to low risk group.

\section{Perinatal Outcome}

Out of 100 patients, 24 had meconium staining of liquor. In high risk group, out of 9 non-reactive tracings 5 had meconium stained liquor (55\%).

In low risk group, out of 2 non-reactive tracing two had meconium staining of liquor $(50 \%)$. Thus, the incidence of meconium staining is more in non-reactive tracings compared to reactive group.

In HR category in non-reactive group, 6 out of 50 i.e. $66.7 \%$ had low Apgar score making the p value 0.0001 , which is statistically significant. In low risk category, out of the 2 cases 1 had low Apgar. All reactive cases had good Apgar score. In high risk cases in reactive traces $7.1 \%$ had low Apgar and in non-reactive cases $25 \%$ had low Apgar.

Analysing NICU care among the high risk patients, $76 \%$ of babies received NICU care, whereas in low risk patients only $18 \%$ received NICU care making it statistically significant as the $p$ value is 0.0001 . The duration of hospital stay was also more in non-reactive admission test babies, a mean of 7 days as compared to 5 days in reactive group in high risk patients. This value is statistically significant as the p value is 0.04 .

In low risk group also, out of 50 babies 9 were admitted in NICU i.e. 8 from reactive category and one from non-reactive category. But since there were only 2 non-reactive tracings, this value is not statistically significant.

\section{Perinatal Mortality}

In 50 low risk cases 48 had reactive traces, out of which 47 (97.9\%) were discharged alive and healthy; 2 patients had non-reactive AT, both the babies expired. P value was 0.0024 . In high risk group out of 50 cases, 41 had reactive traces and 38 (92.2\%) were discharged alive and healthy; 9 had nonreactive traces, 7 babies expired in neonatal period. Perinatal mortality in high risk case is $77.8 \%$.

\section{DISCUSSION}

Comparing the AT results in high risk group, out of 50 patients 41 patients had a reactive AT tracings and 9 had NR AT tracings. In low risk group, 48 patients had reactive tracings and two patients had NRAT tracings. Percentage of non-reactive tracings in high risk group is $18 \%$ and that of reactive group is $4 \%$ only. The total percentage of NRAT in our study is $22 \%$. This is almost similar to other studies found in the literature. Nochimson D J ${ }^{[3]}$ in his study had $23.8 \% \quad(187 / 786)$ non-reactive tracings. Shivani Khandelwal[4] in her study had $24 \%$ non-reactive tracings.

\section{Analysing the Mode of Delivery}

Comparing the rate of LSCS in reactive and non-reactive traces, the rate of LSCS in non-reactive HR group is $88.9 \%$ and in reactive case it is $53.7 \%$. While the rate of LSCS in LR Group in non-reactive cases is $100 \%$ and $22.9 \%$ in reactive traces. KIDD[5] found LSCS rate to be $29 \%$ in a series of 77 patients. Bhide[6] studied NRAT in 143 cases and found the false positive rates for LSCS to be as high as $74.36 \%$.

Phelan J P[7] studied 3000 AT tracings done in 1452 high risk patients and observed that $14 \%$ tests were non-reactive and in these women there were significant increase in LSCS rates for foetal distress and perinatal mortality rates.

In low risk patients in non-reactive category there are two patients, both are delivered by LSCS and had thick meconium stained liquor. Other patient had Intrapartum foetal distress.

\section{LSCS for Intrapartum Foetal Distress}

Out of 100 patients, clinical foetal distress was seen in 8 out of 89 reactive traces (8.9\%) and 2 out of 12 of non-reactive traces (18\%). In high risk group, 3 out of 41 reactive traces 
had clinical foetal distress (7\%). One out of 8 non-reactive had intrapartum foetal distress (12\%).

In low risk group 4 out of 48 reactive traces had intrapartum distress (8.3\%), one of two patients had intrapartum foetal distress (50\%). Thus, clinically detected foetal distress was more common in non-reactive traces in both high and low risk cases compared to low risk group.

Ingermarsson ${ }^{[}[8]$ found that patients with reactive admission test had low rate of intrauterine asphyxia (0.9\%), whereas in $50 \%$ of cases with ominous traces had intrauterine foetal asphyxia with a low scalp $\mathrm{pH}$ and neonatal depression

\section{Perinatal Outcome}

In our study, it is found that in HR category in non-reactive group 6 out of 50 i.e. $66.7 \%$ had low Apgar score making the $\mathrm{p}$ value 0.0001 , which is statistically significant. In low risk category, out of the 2 cases 1 had low Apgar all reactive cases had good Apgar score. Out of 100 patients, 24 had meconium staining of liquor. In high risk group, out of 9 non-reactive tracings 5 had meconium stained liquor (55\%).

In low risk group, out of 2 non-reactive tracing two had meconium staining of liquor (50\%). Thus, the incidence of meconium staining is more in non-reactive tracings compared to reactive group.

In a similar study by Shivani[4] in low risk group in nonreactive traces $50 \%$ had low Apgar in reactive group, $100 \%$ had good Apgar in high risk cases in reactive.

\section{RESULTS AND ANALYSIS}
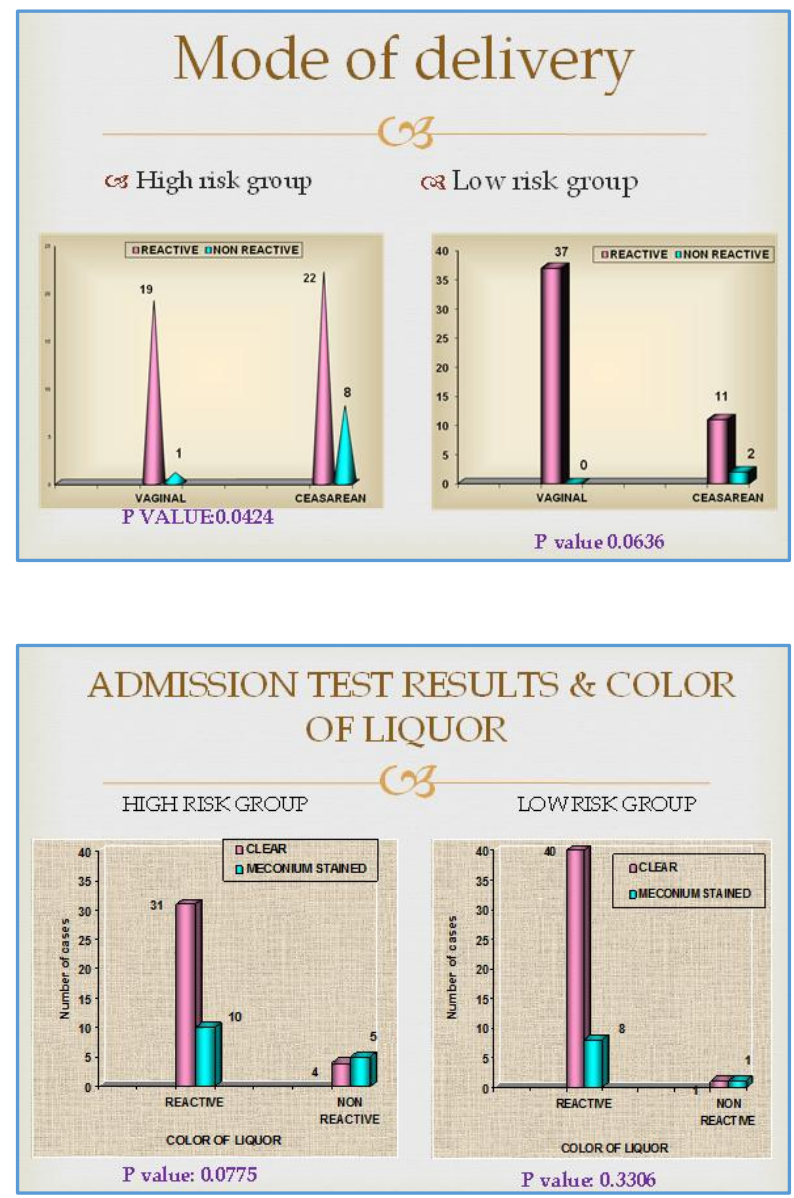
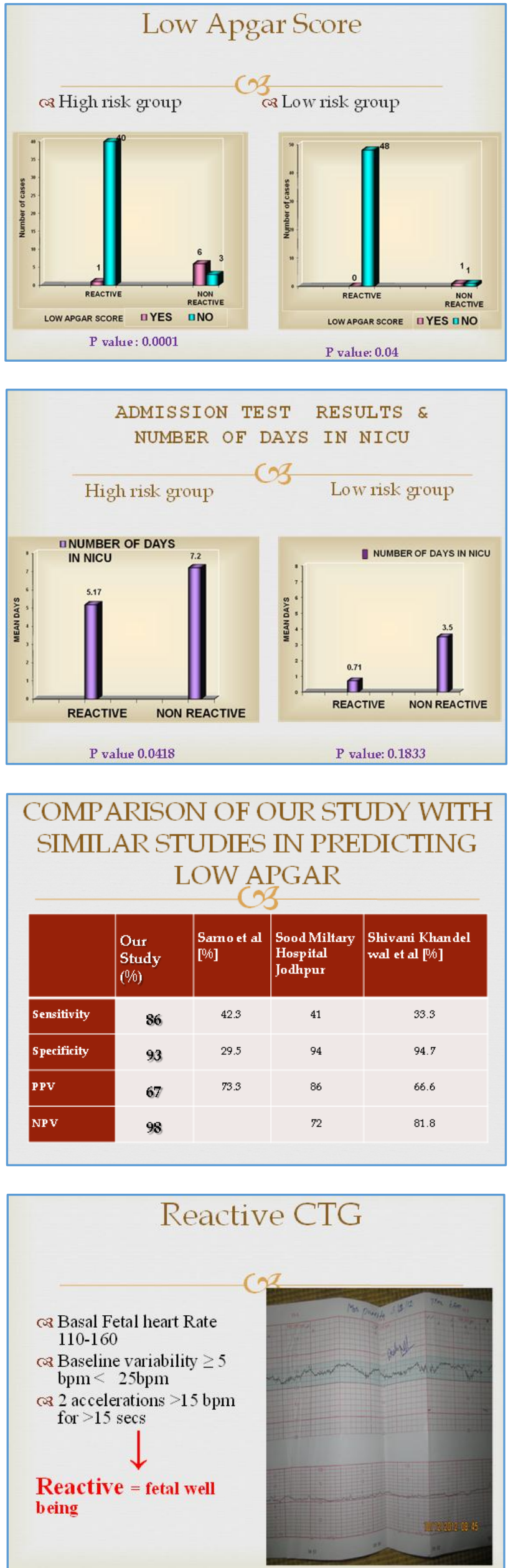
Traces 7.1\% had low APGAR in non-reactive cases $25 \%$ had low APGAR In their study in low risk group, $8.6 \%$ of the patients with reactive AT had meconium stained liquor, whereas $25 \%$ of the patients whose AT was nonreactive had meconium stained liquor. In the high-risk group, $9.5 \%$ of the

\section{Perinatal Mortality}

In our study in 50 low risk cases, 48 had reactive traces, 47 (97.9\%) were discharged alive and healthy; 2 patients had non-reactive AT, both the babies expired. P value was 0.0024 . In high risk group, out of 50 cases 41 had reactive traces, 38 (92.2\%) were discharged alive and healthy; 9 had nonreactive traces, 7 babies expired in neonatal period. Perinatal mortality in high risk case is $77.8 \%$.

\section{Comparison of our Study with Previous Similar Studies in} Predicting Perinatal Mortality

\begin{tabular}{|c|c|c|c|c|c|}
\hline & $\begin{array}{c}\text { Our } \\
\text { Study } \\
\text { (\%) }\end{array}$ & $\begin{array}{c}\text { Sarno } \\
\text { et al } \\
{[\%]}\end{array}$ & $\begin{array}{c}\text { Inger- } \\
\text { marsson } \\
\text { et al [\%] }\end{array}$ & $\begin{array}{c}\text { Sood } \\
\text { Military } \\
\text { Hospital } \\
\text { Jodhpur }\end{array}$ & $\begin{array}{c}\text { Shivani } \\
\text { Khandelwal } \\
\text { et al [\%] }\end{array}$ \\
\hline Sensitivity & 70 & 83.3 & 23.5 & 41 & 33.3 \\
\hline Specificity & 95 & 84.5 & 99.4 & 94 & 94.7 \\
\hline PPV & 78 & 23.8 & 40.0 & 86 & 66.6 \\
\hline NPV & 93 & 98.9 & 98.7 & 72 & 81.8 \\
\hline \multicolumn{7}{|c|}{ Table 3 } \\
\hline
\end{tabular}

From our study, the specificity of AT in predicting perinatal mortality in high risk pregnancies is $95 \%$ and the negative predictive value is $93 \%$. The sensitivity of the test is $70 \%$ and positive predictive value is $78 \%$.

It is almost similar to other International studies; Sarno,[9] in their study in 1989, found specificity and NPV of AT for foetal distress was $84.5 \%$ and $98 \%$. The sensitivity and PPV was found to be $83.3 \%$ and $23.8 \%$ respectively.

Ingermarsson[8] in their study (1986) found out the specificity and NPV value to be $99.4 \%$ and $98.7 \%$ respectively. This value is similar to our study. The sensitivity and PPV was $23.5 \%$ and $40 \%$, respectively.

In a study in Sood Military Hospital, Jodhpur, sensitivity of AT was $94 \%$ and NPV was $72 \%$. The specificity and NPV was $41 \%$ and $86 \%$ respectively. Another study by Shivani[4] sensitivity and NPV for perinatal mortality was $94.7 \%$ and $81.8 \%$, which was almost similar to our study.

\section{CONCLUSION}

By analysing our study carefully and comparing it with similar studies in literature, we can conclude any nonreactive tracings should be extended for 40 minutes along with foetal stimulation to reduce the false positive rates. patients who had admission test reactive had meconium stained liquor whereas $37.5 \%$ of the patient had meconium stained liquor when the AT was nonreactive. So it is observed that occurrence of meconium was high in patients with nonreactive AT in both groups $(\mathrm{p}<0.05)$.

Admission Stress Test increases the rate of LSCS in both high and low risk groups. Non-reactive traces in both high and low risk groups are associated with more foetal distress, low Apgar, prolonged NICU care and increased perinatal mortality.

Admission test may be best recommended as a screening test in all patients irrespective of whether they are high-low risk patients, as the incidence of neonatal morbidity and mortality is high in non-reactive tracings. The limitations of the study are that the present study included only 100 patients in early labour due to time constraints. A large study may be able to better evaluate the AT as screening test for predicting adverse perinatal outcome in high and low risk pregnancies.

\section{REFERENCES}

[1] James DK. High risk pregnancy. 4th edn. Newdelhi, Elsevier 2011:p 1196

[2] Corton MM, Leveno K, Bloom S. Williams obstetrics. 23 ${ }^{\text {rd }}$ edn. New York, McGrawHill 2010:p 338.

[3] Nochimson DJ, Turbeville JS, Terry JE. The nonstress test. Obstet Gynaecol 1978;51(4):419-21.

[4] Khandelwal S, Dhanaraj M. Admission test as precursor of perinatal outcome: a prospective study. Arch Gynecology Obstetric 2010;282:377-82.

[5] Kidd LC, Patel NB, Smith R. Non-stress antenatal cardiotocography-a prospective randomized clinical trial. Br J Obstet Gynaecol 1985;92(11):1156-9.

[6] Arias F, Bhide AG, Arulkumaran S. The Non-stress test. In: practical guide to high risk pregnancy and delivery. Elsevier Health Sciences 2012.

[7] Phelan JP. The nonstress test: a review of 3,000 tests. Am J Obstetric Gynecology 1981;139(1):7-10.

[8] Ingermarsson I, Arulkumaran S, Ingermarsson E, et al. Admission test: a screening test for fetal distress in labor. Obstetrics and Gynecology 1986;68(6):800-6.

[9] Sarno AP, Ahn MO, Brar HS, et al. Intrapartum doppler velocimetry, amniotic fluid volume and fetal heart rate as predictors of subsequent fetal distress. I. An initial report. Am Obstetric Gynecology 1989;161(6 Pt 1):1508-14. 